\title{
The influence of habitat complexity on fish assemblages associated with extractive platforms in the central Mediterranean Sea
}

\author{
Pierpaolo Consoli, ${ }^{1}$ Maria Cristina Mangano,${ }^{2 *}$ Gianluca Sarà, ${ }^{2}$ Teresa Romeo, ${ }^{1,3}$ Franco Andaloro ${ }^{1}$ \\ ${ }^{1}$ Stazione Zoologica Anton Dohrn, Centro Interdipartimentale della Sicilia, Milazzo (ME); ${ }^{2}$ Department of Earth and Marine Sciences, \\ University of Palermo; ${ }^{3}$ Institute for Environmental Protection and Research (ISPRA), BIO-CIT, Palermo, Italy \\ *Corresponding author: mariacristina.mangano@gmail.com
}

\begin{abstract}
In this work the influence of habitat complexity on fish assemblages associated with extractive platforms in the Mediterranean Sea was investigated. More specifically, at large spatial scale we tested the differences in fish assemblage between 4-legs vs 8-legs platforms, whereas at medium scale we evaluated, within each platform, the differences between internal structures with increasing complexity degrees (respectively: the water volume without any pillar - complexity " 0 "; the junction of two pillars - "1"; the junction of four pillars - "2"). Both univariate and multivariate analyses showed highly significant differences for each of the tested factors, as well as for their interaction. In general, at both medium and large spatial scales, mean species richness and abundance were positively correlated with the increasing habitat complexity with the highest values associated with 8-legs platforms and with the most complex internal structures within each platform. According to our findings, a more complex structure is able to attract more fish species and specimens than a less complex one, supporting previous studies carried out on different man-made structures outside the Mediterranean Sea. The study will integrate the still poor available knowledge baseline on the attractive potential of extractive platforms with strong implications for the environmental management under the incoming light of decommission in the basin.
\end{abstract}

Key words: Artificial habitat; Underwater Visual Census; gas platform; species richness.

Received: November 2018. Accepted: November 2018.

\section{INTRODUCTION}

Habitat complexity is defined as the heterogeneity in the arrangement of physical structure in the habitat surveyed (sensu Lassau and Hochuli, 2004) and it represents one among the most important ecological factor in shaping structure and community dynamics. Among others, it influences fish abundance, diversity in terms of species richness and composition (Jones, 1988; Bell and Galzin, 1984; Roberts and Ormond, 1987; Bell et al., 1991; Hixon and Beets, 1993; Warfe and Barmuta, 2004; Harvey et al., 2005; Willis et al., 2005; Mangano et al., 2017).

A particular relationship has been reported for several natural environments between the habitat complexity and animal community structure or assemblage compositions (i.e. both numbers of individuals and numbers of species; Luckhurst and Luckhurst, 1978; Roberts and Ormond, 1987; McClanahan, 1994; McCormick, 1994; Öhman and Rajasuriya, 1998; Gratwicke and Speight, 2005; Garcia Charton and Pérez Ruzafa, 2008; Porporato et al., 2014; Mangano et al., 2015). The main mechanism invoked to explain it, is a reduction of predation pressure due to the increased amount of refuge available to prey species (Hixon and Beets, 1993; Macpherson, 1994; Caley and St. John, 1996; Almany, 2004a). Increase in available refuges due to enhanced substrate topography also has been shown to reduce competition for space (Hixon and Menge, 1991; Almany, 2004b) as well as adding to niche dimensionality (MacArthur and Levins, 1967), both of which potentially increase fish abundance and distribution. The same pattern among spatial complexity, fish abundance and species richness has also been reported for artificial habitats such as, for instance, extractive platforms (Chang et al., 1977; Higo et al., 1980; Buckley, 1982; Shulman, 1984; Chandler et al., 1985; Roberts and Ormond, 1987; Gorham and Alevizon, 1989; Hixon and Beets, 1989; Bohnsack et al., 1991; Love and York, 2006). Surprisingly, the largest amount of these evidence has been collected outside the Mediterranean Sea, where in spite of the large number of oil and gas extractive platforms, this aspect is still poorly studied (Fabi et al., 2002, 2004; Consoli et al., 2007, 2013; Andaloro et al., 2011, 2012; Scarcella et al., 2011; Mangano and Sarà, 2017).

The extraction of fossil fuels from offshore fields has strongly increased over the last decades to meet the global growing demand for energy (Ghisel, 1997; Terlizzi et al., 2008), this implies that the number of offshore platforms has increased the world over and, most probably, it will further increase in the future (De Luca, 1999; Pulsipher and Daniel, 2000). 
Then, understanding the role played by offshore platforms in shaping multi-level marine ecosystem's dynamics is becoming pressing as offshore platforms are acquiring increasing importance worldwide for its implications on marine biodiversity (Mangano and Sarà, 2017). The aim of the present study was to evaluate the influence of habitat complexity on fish assemblages associated with extractive platforms in the Ionian Sea (Mediterranean Sea). The obtained outcomes integrate the still poor available knowledge baseline on the attractive potential of these human-made structures with interesting rebounds for the environmental management in a context foreseen of decommission in the basin. In doing so, we tested whether different complexity degrees affected the associated fish assemblages across two different spatial scales. Accordingly, 1) we tested the difference in fish assemblage at large scale $(-10 \mathrm{Km})$ between two different levels of complexity (4-legs vs 8-legs platforms) and 2), at medium scale $(-100 \mathrm{~m})$ testing the difference in fish assemblage between internal structures, of such platforms, with different spatial complexity.

\section{METHODS}

\section{Study sites}

The study was carried out during one week in May 2006 at three offshore gas platforms (Luna A, Luna B and Hera Lacinia) located in the southern Ionian Sea (Central Mediterranean Sea) respectively, 5.3, 6.2 and $2.6 \mathrm{Km}$ offshore (Fig. 1). Two of them (Luna A and Luna B) were 8-leg platforms while the third one (H. Lacinia) was a 4leg platform. All these platforms lie on a sandy seabed and are fixed to the sea floor by concrete or steel legs, which are connected by an assemblage of cross beams. The platforms were colonized by several foulers that generally provide crevices, refuges and food to cryptic and nekto-benthic fish species. The most abundant sessile species was the bivalve Mytilus galloprovincialis followed by balanids, Ostrea sp., and Arbacia lixula (P. Consoli, personal observation).

\section{Habitat complexity}

For each of the three platforms, internal structures with increasing complexity degrees (hereafter complexity 0,1 and 2; Fig. 2), were identified and corresponded to: $0=$ the water volume without any pillar; $1=$ the junction of two pillars; and $2=$ the junction of four pillars, respectively.

Fish species and their abundances were recorded by Underwater Visual Censuses (UVC) by deploying the "Mobile Point Count" (MPC) technique performed at a depth between 0 and 12 meters. This technique, specifically designed for offshore platforms by Rilov and Benayahu (2000) and applied by Consoli et al. (2007,
2013) and Andaloro et al. (2011, 2012) in the Mediterranean Sea, was chosen as it is highly reliable in studying species strictly associated with the pillars and to detect benthic and cryptic species (Andaloro et al., 2011, 2012; Consoli et al., 2007, 2013). The diver, turning around each unit and looking at towards the pillar, counted all fishes occurring up to $3 \mathrm{~m}$ from the pillar. First, the diver recorded the more conspicuous and easily identifiable fishes from a maximum distance of 3 meters from the pillar (so that to have an entire view of the census unit) and then straight after, approached to the pillar, and counted the benthic and crypto-benthic species.

The total censused volume for complexity 0 corresponded to a cylinder of $7 \mathrm{~m}$ of diameter and $6 \mathrm{~m}$ height $\left(\sim 231 \mathrm{~m}^{3}\right)$. As regard complexity 1 and 2, the censused water volume was obtained subtracting the volume of the pillars ( $1 \mathrm{~m}$ of diameter) from $231 \mathrm{~m}^{3}$. The resulting volumes for complexities 1 and 2 were 224 and $219 \mathrm{~m}^{3}$, respectively. As a main consequence, data of abundance were standardized to the maximum censused volume $\left(231 \mathrm{~m}^{3}\right)$ in order to compare censuses performed next to the different spatial complexity structures. Forty-



Fig. 1. Study area located in the Ionian Sea off Crotone (Calabria, Italy). 
eight censuses were performed for each level of medium scale complexity at each platform, leading to a total of 432 observations in the data set.

\section{Statistical analyses}

The sampling design included 2 factors:

i) Large Scale Complexity (LSC) was a fixed factor in the analysis with 2 levels of large-scale complexities (as expressed by: 4-leg and 8-leg platforms).

ii) Medium Scale Complexity (MSC) was a fixed factor in the analysis with 3 levels: complexity 0,1 and 2 according to the rationale presented before and represented in Fig. 2.

On this basis, a two-ways Permutational Analysis of Variance (PERMANOVA; Anderson, 2001, McArdle and Anderson, 2001) was performed on abundance data to test the null hypothesis of no significant differences between fish assemblages associated with increasing habitat complexities, at two different spatial scales. The analysis was based on Bray-Curtis dissimilarities, calculated on log-transformed fish assemblage matrix. Each term of the analysis was tested using 9999 random permutations of appropriate units (Anderson and ter Braak, 2003). Significant terms that were relevant to our hypothesis were investigated using a posteriori pair-wise comparison with the PERMANOVA $t$-statistic and 9999 permutations.

Furthermore, we tested the effect of response variables on community metrics and in doing so, we modelled overall fish abundance and species richness through a Permutational univariate analyses of Variance (PERMANOVA; Anderson, 2001; McArdle and Anderson, 2001). Here we used the Euclidean distance instead the Bray-Curtis similarity index. Thus, the same F-statistics were calculated, but P-values were obtained by permutation. Finally, the SIMPER similarity percentage procedure (Clarke, 1993) was used to identify the fish species that most contributed to the differences among spatial complexities at medium and large spatial scale. All the analyses were performed using PRIMER 6 software package with PERMANOVA+add-on (Anderson et al., 2008).

\section{RESULTS}

In Tab. 1 mean abundances and standard errors of each species are showed for LSC and MSC factors. Overall 15 fish taxa belonging to 6 families were recorded in the study area. Most of the recorded species were nektobenthonic, while only 5 pelagic species were observed.

In term of species richness, Sparids were the most important family being represented by six species whereas the most abundant species were Boops boops, Anthias anthias and Chromis chromis.

PERMANOVA of the total fish assemblage (abundance data) showed highly significant differences for each factor considered in the analysis (Tab. 2) and also for the interaction between factors LSC and MSC (PERMANOVA, $\mathrm{P}=0.001$ ). Furthermore, pairwise comparisons showed that significant differences occurred between fish assemblages in every MSC comparisons within each LSC level $(\mathrm{P}<0.001)$. The greatest $t$-values were observed between MSC 0-level and 2-level at both 4- and 8-legs platforms $(\mathrm{t}=3.85$ and $\mathrm{t}=5.26$, respectively; Tab. 2$)$.

PERMANOVA on overall abundance and species richness mirrored the results of multivariate analysis (Tab. 2). According to the large-scale complexity, the highest values of both metrics were associated with 8-legs platforms ( $\mathrm{S}=2.62$ and $1.58, \mathrm{~N}=237$ and 56 , respectively at 8-legs and 4-legs platforms; Fig. 3).
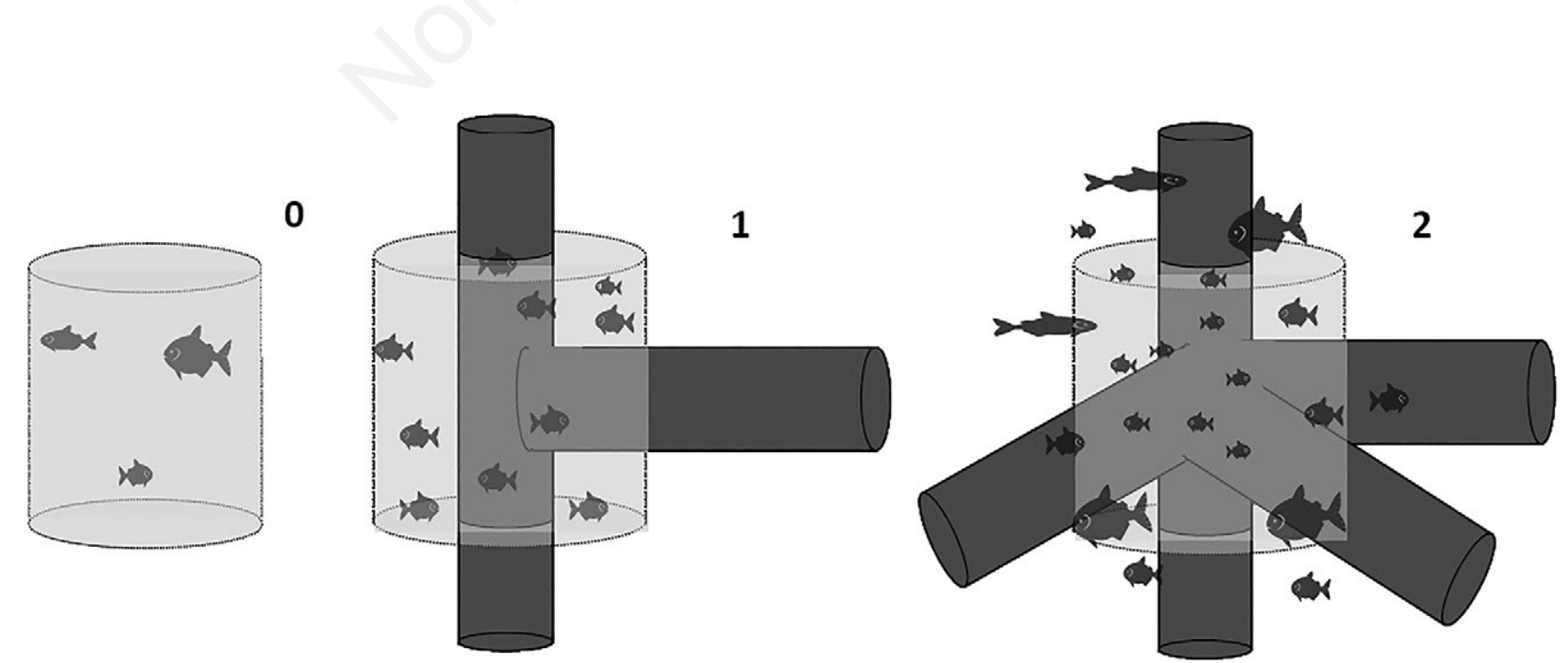

Fig. 2. Internal structures with increasing degrees of complexity; identified and corresponded to: $0=$ the water volume without any pillar; $1=$ the junction of two pillars; and 2=the junction of four pillars, respectively. 
As regards mean species richness, significant differences were found, at each platform, among MSC levels (Tab. 2) and the highest values were always associated with structures of Compl 2 (Fig. 3; Tab. 2). Looking at the $t$ value, the greatest differences occurred between complexity $0-2(t=17.747$ and $t=9.7555$, at 8 legs and 4-legs platforms, respectively, Tab. 2).

A similar pattern was observed, at 8-legs platforms, also for the mean abundance, whereas, at the 4-legs platform, the highest value was associated with level 0 of MSC (Compl 0; Fig. 3).

SIMPER procedure pinpointed some fish taxa as the major contributors to the dissimilarities among spatial complexities. High densities of Boops boops, Anthias anthias and Chromis chromis characterized the censuses carried out nearby the most complex structures, both at large and medium spatial scale (Tab. 3).

\section{DISCUSSION}

Fish assemblages associated with increasing habitat complexities showed differences in terms of species richness, abundance and assemblages structure. This

Tab. 1. Mean species abundances and standard errors ( \pm SE) per sample unit $\left(230.91 \mathrm{~m}^{3}\right)$ for each level (Compl 0,1 and 2$)$ of complexity factors at 4-legs vs 8-legs platforms.

\begin{tabular}{|c|c|c|c|c|c|c|c|c|c|c|c|c|c|}
\hline \multirow[t]{2}{*}{$\begin{array}{l}\text { Platform } \\
\text { complexity }\end{array}$} & \multirow[t]{2}{*}{$\begin{array}{cc}\text { Ecological LSC } \\
\text { category MSC }\end{array}$} & \multicolumn{6}{|c|}{ 4-legs } & \multicolumn{6}{|c|}{ 8-legs } \\
\hline & & Mean & SE & Mean & $\mathrm{SE}$ & Mean & SE & Mean & SE & Mean & SE & Mean & SE \\
\hline Anthias anthias & NB & & & & & & & 31.53 & 11.85 & 86.14 & 14.39 & 187.00 & 21.95 \\
\hline Boops boops & $\mathrm{P}$ & 30.00 & 6.99 & 24.54 & 8.88 & 23.84 & 6.29 & 31.31 & 7.04 & 56.85 & 11.60 & 137.29 & 19.23 \\
\hline Chromis chromis & NB & 0.42 & 0.42 & 1.83 & 0.62 & 18.90 & 5.21 & 5.81 & 1.78 & 18.77 & 3.05 & 57.75 & 7.92 \\
\hline Diplodus sargus & NB & & & & & 0.07 & 0.04 & & & 0.01 & 0.01 & 0.01 & 0.01 \\
\hline Diplodus vulgaris & NB & & & 0.02 & 0.02 & 0.51 & 0.16 & 0.94 & 0.38 & 0.82 & 0.31 & 1.01 & 0.22 \\
\hline Oblada melanura & $\mathrm{P}$ & 0.94 & 0.59 & 0.09 & 0.09 & 0.81 & 0.46 & 13.69 & 4.10 & 0.43 & 0.43 & 0.92 & 0.83 \\
\hline Sarpa salpa & NB & & & & & & & 0.04 & 0.04 & & & 0.01 & 0.01 \\
\hline Seriola dumerili & $\mathrm{P}$ & & & 0.02 & 0.02 & & & & & & & & \\
\hline Serranus cabrilla & NB & & & 0.02 & 0.02 & 0.11 & 0.06 & & & & & 0.01 & 0.01 \\
\hline Serranus scriba & NB & & & & & & & & & & & 0.02 & 0.02 \\
\hline Spicara flexuosa & $\mathrm{P}$ & 26.15 & 9.12 & 13.00 & 5.17 & 14.06 & 5.92 & 4.24 & 1.39 & 13.58 & 5.48 & 32.69 & 7.91 \\
\hline Spondyliosoma cantharus & NB & & & & & & & 0.02 & 0.01 & 0.02 & 0.02 & 0.10 & 0.04 \\
\hline Thalassoma pavo & NB & - & Pre & 1.35 & 0.48 & 1.74 & 0.46 & 0.01 & 0.01 & 2.74 & 0.59 & 10.98 & 1.42 \\
\hline Trachurus spp. & $P$ & 9.38 & 4.25 & 0.86 & 0.60 & 0.44 & 0.44 & 1.77 & 1.12 & 1.92 & 1.15 & 13.44 & 6.66 \\
\hline
\end{tabular}

LSC, large scale complexity; MSC, medium scale complexity; NB, necto-benthonic; P, pelagic.

Tab. 2. Results of PERMANOVA tests analysing the effect of LSC and MSC factors on fish assemblage (multivariate test), species richness and fish abundance (univariate tests). Results of pair-wise tests performed for the interaction factor "LSC x MSC" are also reported.

\begin{tabular}{|c|c|c|c|c|c|c|c|c|c|c|}
\hline \multirow[t]{2}{*}{ Source } & \multicolumn{4}{|c|}{ Fish assemblage } & \multicolumn{3}{|c|}{ Species richness } & \multicolumn{3}{|c|}{ Abundance } \\
\hline & df & MS & $\mathbf{F}$ & $\mathbf{P}$ & MS & F & $\mathbf{P}$ & MS & $\mathbf{F}$ & $\mathbf{P}$ \\
\hline LSC & 1 & 75,363 & 4.0051 & 0.002 & 102.78 & 50.627 & 0.001 & $3.14 \mathrm{E}+06$ & 54.959 & 0.001 \\
\hline MSC & 2 & 52,279 & 16.826 & 0.001 & 133.95 & 113.99 & 0.001 & $2.15 \mathrm{E}+06$ & 25.179 & 0.001 \\
\hline LSC $x$ MSC & 2 & 18,817 & 6.0562 & 0.001 & 10.616 & 9.0341 & 0.001 & $2.14 \mathrm{E}+06$ & 25.024 & 0.001 \\
\hline Res & 426 & 3107 & & & 1.1751 & & & $1.82 \mathrm{E}+07$ & & \\
\hline 8-legs platforms & & & $t$ & $\mathbf{P}$ & & $t$ & $\mathbf{P}$ & & $t$ & $\mathbf{P}$ \\
\hline Compl 0. Compl 1 & & & 3.8476 & 0.001 & & 10.934 & 0.001 & & 3.9496 & 0.001 \\
\hline Compl 0. Compl 2 & & & 5.2578 & 0.001 & & 17.747 & 0.001 & & 9.1615 & 0.001 \\
\hline Compl 1. Compl 2 & & & 2.754 & 0.001 & & 5.2947 & 0.001 & & 6.3641 & 0.001 \\
\hline 4-legs platforms & & & & & & & & & & \\
\hline Compl 0. Compl 1 & & & 2.3831 & 0.001 & & 2.8711 & 0.001 & & 1.2443 & 0.226 \\
\hline Compl 0. Compl 2 & & & 3.8503 & 0.001 & & 9.7555 & 0.001 & & 0.31125 & 0.772 \\
\hline Compl 1. Compl 2 & & & 1.8512 & 0.009 & & 3.9344 & 0.001 & & 0.95222 & 0.349 \\
\hline
\end{tabular}

df, degree of freedom; LSC, large scale complexity; MSC, medium scale complexity. 
result was observed at both investigated spatial scales. In particular, as far as medium spatial scale is concerned, a positive relationship was observed between increasing habitat complexity and mean species richness at both levels of large spatial complexity (4- and 8-legs platforms). The same pattern was detected for mean fish abundance at the most complex platforms, while at 4-legs platform, a clear pattern was not observed since the highest values were not associated with the most complex internal structures. In this less complex platform, internal structure, corresponding to different degree of medium spatial scale complexities, are usually closer to each other compared with those at 8-legs platforms. Then, fishes probably, could not be able to distinguish these different degrees of spatial complexities. Mean fish abundance and species richness resulted positively correlated with increasing complexities also at large spatial scale.

These results strengthen and confirm observations made in previous studies carried out on different man-made structures such as artificial reefs (Roberts and Ormond ,1987; Hixon and Beets, 1989; Chang et al., 1977; Higo et al., 1980; Buckley, 1982; Gorham and Alevizon, 1989; Bohnsack et al., 1991; Charbonnel et al., 2002, Gratwicke and Speight, 2005), fringing reef (Roberts and Ormond 1987), shipwrecks (Chandler et al., 1985; Fagundes-Netto et al., 2011; Consoli et al., 2015) and extractive platforms (Love et al., 2003, 2010, 2012; Love and York, 2006; Rilov and Benayahu, 1998, 2000, 2002; Rooker et al., 1997;
Consoli et al., 2013). All these studies proved a positive relationship between fish species-richness/abundance and the increasing habitat complexity.

After all, it is well known that these artificial habitats promote the aggregation of fishes that would otherwise be dispersed across larger areas of the ocean, a result of peculiar interest in the Mediterranean basin, locally characterized by a very peculiar hydrodynamic system (Hastings et al., 1976; Aabel et al., 1977; Driessen, 1985; Gallaway et al., 1981; Bohnsack and Sutherland, 1985; Love and Westphal, 1990; Bull and Kendall, 1994; Kasprzak, 1998; Minton and Heath, 1998; Jørgensen et al., 2002; Løkkeborg et al., 2002; Love et al., 2003; Love and York, 2006; Andaloro et al., 2011, 2012; Consoli et al., 2007, 2013; Capodici et al., 2018). In particular, as regard extractive platforms, as these structures extend throughout the entire water column, their effects are not confined to demersal fishes, but also involve pelagic species that congregate about them, attracted either by the solid reeflike nature of the supporting structures, or by the numerous smaller forage organisms in the area (Bombace et al., 1999, Fabi et al., 2002, Relini et al., 1976, Stanley and Wilson, 1991). The reason is that fishes use these artificial structures, for shelter, feeding, spawning, and orientation (Kojima, 1956; Hunter and Mitchell, 1967; Gooding and Magnuson, 1967; Luckhurst and Luckhurst, 1978; Kakimoto, 1982; Ogawa, 1982; Steimle and Ogren, 1982; Yoshimuda, 1982; Kellison and Sedberry, 1998; Rilov and
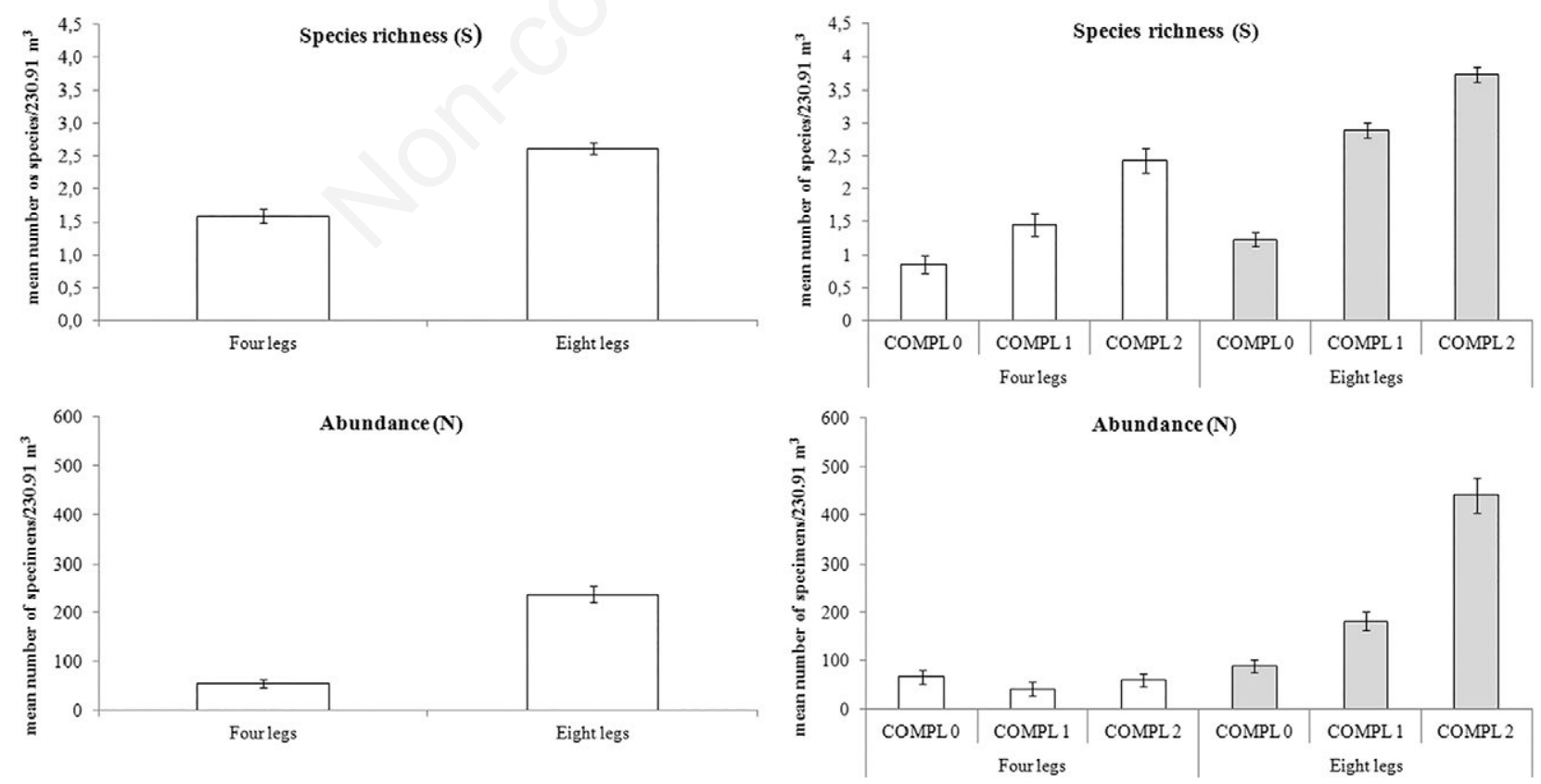

Fig. 3. Mean number of species and specimens for each combination of levels of factor MSC within each level of LSC. Bars represent standard errors. 
Benayahu, 1998; Caselle et al., 2002; Castriota et al., 2011; Fabi et al., 2006; Leitão et al., 2007). Indeed, extractive platforms can furnish shelter for protection from predation, additional food supply and spawning substrate, and can act as a visual attractant for organisms not strictly dependent on hard bottoms (Fabi et al., 1998).

Then, according to these findings, a more complex structure is able to attract more fish species and specimens than a less complex one. In particular, what we observed is that most of the pelagic and demersal fishes were particularly abundant where cross beams and vertical beams cross each other. At these junctions, there is a greater available surface that species such as $C$. chromis, $A$. anthias and B. boops use like shelter in case of strong

Tab. 3. SIMPER of the fish taxa contributing most (\%) to the dissimilarity, on large spatial scale, between 4-legs $v s$-legs platforms and, on medium scale, among internal structures with increasing complexity degrees (Compl 0, 1 and 2).



\begin{tabular}{|c|c|c|c|}
\hline \multicolumn{4}{|c|}{$\begin{array}{l}\text { Compl } 0 \text { - Compl } 1 \\
\text { Average dissimilarity=86.06 }\end{array}$} \\
\hline Boops boops & 3.2 & 3.91 & 28.1 \\
\hline Anthias anthias & 1.14 & 4.1 & 23.82 \\
\hline Chromis chromis & 0.65 & 2.25 & 17.02 \\
\hline Spicara flexuosa & 1.26 & 1.36 & 10.11 \\
\hline Thalassoma pavo & 0.01 & 0.93 & 9.39 \\
\hline Oblada melanura & 0.98 & 0.06 & 5.74 \\
\hline
\end{tabular}



\begin{tabular}{|c|c|c|c|}
\hline \multicolumn{4}{|c|}{$\begin{array}{l}\text { Compl } 1 \text { - Compl } 2 \\
\text { Average dissimilarity=68.01 }\end{array}$} \\
\hline Boops boops & 3.91 & 6.21 & 25.96 \\
\hline Anthias anthias & 4.1 & 6.96 & 25.08 \\
\hline Chromis chromis & 2.25 & 4.9 & 20.63 \\
\hline Thalassoma pavo & 0.93 & 2.07 & 10.91 \\
\hline Spicara flexuosa & 1.36 & 2.19 & 9.32 \\
\hline
\end{tabular}

Av. abund., average abundance. 
currents. C. chromis and A. anthias also use junctions as refuges where to lay eggs: obviously in these places they can better defence the nest from the aggregation of Thalassoma pavo specimens, which frequently attacked and destroyed the benthic nests of these two species.

Moreover, at medium spatial scale, more complex structures provide shelter from predation and current for juvenile and adult fishes: in fact, in case of strong water current many fish species were observed to take refuge on the undercurrent side of these more complex structures.

Once an industrial decision is made to cease oil and gas production, managers must decide what to do with the structure, a process known as decommissioning and over which a huge debate is animating both scientific communities, stakeholder and common opinion from scientific literature to media (Jørgensen et al., 2002; Love et al., 2003; Schroeder et al., 2004; Mangano and Sarà, 2017; Lucifredi, 2018). The process of decommissioning can be addressed in many ways, from the leaving most part of the structures in place to complete removal. Oil and gas platforms have finite economic lives and in the next few decades, several platforms in Mediterranean Sea will be decommissioned being nearing the end of their economic lives. Management decisions regarding the decommissioning of oil and gas platforms will be based on both biological and socioeconomic knowledge baseline (Mangano and Sarà, 2018), which are essential in evaluating the efficacy of any potential rigs-to-reef program.

\section{CONCLUSIONS}

The present results could bear strong implications for the environmental management of decommissioned platforms in this basin because the possibility of knowing the attractive potential of an extractive platform could be an important issue in the decommissioning process aiding legislators and resource managers. Moreover, further comparative, long-term and at larger spatial scale, studies should be funded in other Mediterranean gas/oil platforms, in order to investigate specific cases and propose to maintain a platform rather than another at the end of its life and then lunch a rig-to-reef program enhancing fishery production. Apart from the international recommendation on decommissioning options, (i.e. once the topside is removed total removal, partial removal, leave in place; OSPAR 1982, Hamzah 2003) and some case studies from the North Seas in a European context (e.g. the Indefatigable - Inde - Field Platforms Decommissioning Project), no specific regulation on decommissioning are prescribed in Italy (Legislative Decree no 257/2016). Under the light of the existing literature (Mangano and Sarà, 2017) future multi-criteria analysis for decommissioning options selection might take into account looking for potential alternative use (e.g. energy production), scientific (e.g. artificial reef monitoring) commercial (e.g. aquaculture, tourism and recreation) and multipurpose (all the above).

\section{REFERENCES}

Aabel JP, Cripps S, Kjeilen G, 1997. Oil and gas production structures as artificial reefs, p. 391-404. In: A.C. Jensen (ed.), Proceedings of the 1st EARRN Conference, Ancona, Italy. European Artificial Reef Research. Southampton Oceanography Centre Press, Southampton.

Almany GR, 2004a. Differential effects of habitat complexity, predators and competitors on abundance of juvenile and adult coral reef fishes. Oecologia 141:105-113.

Almany GR, 2004b. Does increased habitat complexity reduce predation and competition in coral reef fish assemblages? Oikos 106:275-284.

Andaloro F, Castriota L, Ferraro M, Romeo T, Sarà G, Consoli P, 2011. Evaluating fish assemblages associated with gas platforms: evidence from visual census techniques and experimental fishing surveys. Cienc. Mar. 37:1-9.

Andaloro F, Ferraro M, Mostarda E, Romeo T, Consoli P, 2012. Assessing the suitability of a remotely operated vehicle (ROV) to study the fish community associated with offshore gas platforms in the Ionian Sea: a comparative analysis with underwater visual censuses (UVCs). Helgoland Mar. Res. 67:241-250.

Anderson MJ, 2001. A new method for non-parametric multivariate analysis of variance. Austral Ecology 26:32-46.

Anderson MJ, Gorley RN, Clarke KR, 2008. PERMANOVA+ for PRIMER: Guide to Software and Statistical Methods. Plymouth, UK: PRIMER-E.

Anderson MJ, ter Braak CJF, 2003. Permutation tests for multifactorial analysis of variance. J. Stat. Comput. Sim. 73: 85-113.

Bell JD, R Galzin, 1984. Influence of live coral cover on coral reef fish communities. Mar. Ecol. Prog. Ser. 15:265-274.

Bell SS, McCoy ED, Mushinsky HR, 1991. Habitat structure: the physical arrangement of objects in space. Chapman and Hall, London.

Bombace G, Fabi F, Rivas G, 1999. Effetti sul popolamento ittico indotti da una piattaforma estrattiva dell'alto adriatico: prospettive di gestione delle risorse costiere. Biol. Mar. Medit. 6:64-72.

Bohnsack JA, Johnson DL, Ambrose RF 1991. Ecology of artificial reef habitats and fishes, p. 61-107. In: W, Seaman Jr and L.M. Sprague (eds.), Artificial habitats for marine and freshwater fisheries. Academic Press, San Diego.

Bohnsack JA, Sutherland DL, 1985. Artificial reef research: a review with recommendations for future priorities. Bull. Mar. Sci. 37: 11-39.

Buckley RM 1982. Marine habitat enhancement and urban recreational fishing in Washington. Mar. Fish. Rev. 44:28-37.

Bull AS, Kendall JJ Jr, 1994. An indication of the process: offshore platforms as artificial reefs in the Gulf of Mexico. Bull Mar Sci 55: 1086-1098.

Caley MJ, St. John J, 1996. Refuge availability structures assemblages of tropical reef fishes. J. Anim. Ecol. 65:414-428.

Caselle JE, Love MS, Fusaro C, Schroeder D, 2002. Trash or 
habitat? Fish assemblages on offshore oilfield seafloor debris in the Santa Barbara Channel, California. ICES J. Mar. Sci. 59:258-265.

Castriota C, Falautano M, Finoia MG, Consoli P, Pedà C, Esposito V, Battaglia P, Andaloro F. 2011. Trophic relationships among scorpaeniform fishes associated with gas platforms. Helgoland Mar. Res. 66:401-411.

Chandler CR, Sanders RM Jr, Landry AM Jr, 1985. Effects of three substrate variables on two artificial reef fish communities. Bull. Mar. Sci. 37:129-142.

Chang K, Lee SC, Shao KT, 1977. Evaluation of artificial reef efficiency based on the studies of model reef fish community installed in northern Taiwan. Bull. Inst. Zool. Acad. Sin. 16:23-36.

Charbonnel E, Serre C, Ruitton S, Harmelin JG, Jensen A, 2002. Effects of increase habitat complexity on fish assemblages associated with large artificial reef units (French Mediterranean coast). ICES J. Mar. Sci. 59:208-213.

Clarke KR, 1993. Non-parametric multivariate analyses of changes in community structure. Aust. J. Ecol. 18:117-143.

Capodici F, Ciraolo G, Cosoli S, Maltese A, Mangano MC, Sarà G, 2018. Downscaling hydrodynamics features to depict causes of major productivity of Sicilian-Maltese area and implications for resource management. Sci. Total Environ. 628:815-825.

Consoli P, Azzurro E, Sarà G, Ferraro M, Andaloro F, 2007. Fish diversity associated to gas platforms: evaluation of two underwater visual census. Cienc. Mar. 33:121-132.

Consoli P, Martino A, Romeo T, Sinopoli M, Perzia P, Canese S, Vivona P, Andaloro F, 2015. The effect of shipwrecks on associated fish assemblages in the Central Mediterranean Sea. J. Mar. Biol. Assoc. UK 95:17-24.

Consoli P, Romeo T, Ferraro M, Sarà G, Andaloro F, 2013. Factors affecting fish assemblages associated with gas platforms in the Mediterranean Sea. J. Sea. Res. 77:45-52.

De Luca M, 1999. International report. Offshore 6:38-50.

Driessen PK, 1985. Studing "Neptune's Gallery". Sea Technol. 26:34-38.

Fabi G, Camilletti E, Ciccotti E, Luccarini F, Lucchetti A, Panfili M, Solustri C, 1998. Ruolo trofico della barriera artificiale di Cesano-Senigallia nei confronti di alcune specie ittiche. Biol. Mar. Medit. 5:1812-1821.

Fabi G, Grati F, Lucchetti A, Trovarelli L, 2002. Evolution of the fish assemblage around a gas platform in the northern Adriatic Sea. ICES J. Mar. Sci. 59:309-315.

Fabi G, Grati F, Puletti M, Scarcella G 2004. Effects on fish community induced by installation of two gas platforms in the Adriatic Sea. Mar. Ecol. Prog. Ser. 273:187-194.

Fabi G, Manoukian S, Spagnolo A, 2006. Feeding behavior of three common fishes at an artificial reef in the Northern Adriatic Sea. Bull. Mar. Sci. 78:39-56.

Fagundes-Netto EB, Gaelzer LR, Coutinho R, Zalmon IR, 2011. Influence of a shipwreck on a nearshore-reef fish assemblages off the coast of Rio de Janeiro, Brazil. Lat. Am. J. Aquat. Res. 39:103-116.

Gallaway BJ, Martin LR, Howard RL, Boland GS, Dennis GD, 1981. Effects on artificial reef and demersal fish and macrocrustacean communities. Mar. Sci. 14:237-299.

Garcia Charton JA, Pérez Ruzafa A, 2008. Correlation between habitat structure and a rocky reef fish assemblage in the southwest Mediterranean. Mar. Ecol. 19:111-128.
Ghisel RG, 1997. Fifty years of offshore oil, gas development. Hart Publications, Houston.

Gooding RM, Magnusson JJ, 1967. Ecological significance of a drifting object to pelagic fishes. Pac. Sci. 21 486-497.

Gorham JC, Alevizon WS, 1989. Habitat complexity and the abundance of juvenile fishes residing on small scale artificial reefs. Bull. Mar. Sci. 44:662-665.

Gratwicke B, Speight MR 2005. The relationship between fish species richness, abundance and habitat complexity in a range of shallow tropical marine habitats. J. Fish. Biol. 66:650-667.

Hamzah BA, 2003. International rules on decommissioning of offshore installations: some observations. Mar. Pol. 27:339-348.

Harvey BC, White JL, Nakamoto RJ, 2005. Habitat specific biomass, survival, and growth of rainbow trout (Oncorhynchus mykiss) during summer in a small coastal stream. Can. J. Fish. Aquat. Sci. 62:650-658.

Hastings RW, Ogren LH, Mabry MT, 1976. Observations on fish fauna associated with offshore platforms in the northeastern Gulf of Mexico. Fish. Bull. 74:387-340.

Higo N, Hashi H, Takahama I, Tabata S, Nagashima M, Sakono S, Kasmimizutara T, Yamasaki T 1980. On the fish gathering effect of the artificial reefs ascertained by the diving observation VII at the sea off Maskurazak City. Mem. Faculty Fisheries, Kagoshima Univ. 29:51-63.

Hixon MA, Beets JP, 1989. Shelter characteristics and Caribbean fish assemblages: experiments with artificial reefs. Bull. Mar. Sci. 44:666-680.

Hixon MA, Beets JP, 1993. Predation, prey refuges, and the structure of coral-reef fish assemblages. Ecol. Monogr. 63:77-101.

Hixon MA, Menge BA, 1991. Species diversity: prey refuges modify the interactive effects of predation and competition. Theor. Popul. Biol. 39:178-200.

Hunter JR, Mitchell CT, 1967. Association of fishes with flotsam in the offshore waters of central America. Fish. Bull. 66:13-29.

Jones GP, 1988. Experimental evaluation of the effects of habitat structure and competitive interactions on the juveniles of two coral reef fishes. J. Exp. Mar. Biol. Ecol. 123:115-126.

Jørgensen T, Løkkeborg S, Soldal AV, 2002. Residence of fish in the vicinity of a decommissioned oil platform in the North Sea. ICES J. Mar. Sci. 59:288-293.

Kakimoto H, 1982. The stomach contents of species of fish caught in artificial reefs, p. 271-273. In: S.F Vik (ed.), Japanese artificial reef technology. Tech. Rep. 604. Aquabio, Inc., Annapolis.

Kasprzak RA, 1998. Use of oil and gas platforms as habitat in Louisiana's artificial reef program. Gulf. Mex. Sci. 16:37-45.

Kellison GT, Sedberry GR, 1998. The effects of artificial reef vertical profiles and hole diameter on fishes off South Carolina. Bull. Mar. Sci. 62:763-780.

Kojima S 1956. Fishing for dolphins in the western part of the Japan sea. II. Why do fish take shelter under floating materials? Bull. Jpn. Soc. Sci. Fish. 21:1049-1052.

Lassau SA, Hochuli DF, 2004. Effects of habitat complexity on ant assemblages. Ecography 27:157-164.

Leitão F, Santos MN, Monteiro CC, 2007. Contribution of artificial reefs to the diet of the white sea bream (Diplodus sargus). ICES J. Mar. Sci. 64:473-478.

Løkkeborg S, Humborstad OB, Jørgensen T, Soldal AV, 2002. 
Spazio-temporal variations in gillnet catch rates in the vicinity of North Sea oil platforms. ICES J. Mar. Sci 59:294-299.

Love MS, Nishimoto MM, 2012. Completion of fish assemblage surveys around manmade structures and natural reefs off California. BOEM OCS Study 2012-020, Marine Science Institute, University of California, Santa Barbara.

Love MS, Nishimoto MM, Schroeder DM, 2010. Fish assemblages associated with platforms and natural reefs in areas where data are non-existent or limited. BOEM OCS Study 2010-012, Marine Science Institute, University of California, Santa Barbara.

Love MS, Schroeder DM, Nishimoto MM, 2003. The ecological role of oil and gas production platforms and natural outcrops on fishes in southern and central California: a synthesis of information. OCS Study MMS 2003-032, US Department of the Interior, US Geological Survey, Biological Resources Division, Seattle.

Love MS, York A, 2006. The role of bottom crossbeam complexity in influencing the fish assemblages at California oil and gas platforms. Fish. Bull. 104:542-549.

Love MS, Westphal W, 1990. Comparison of fishes taken by a sportfishing party vessel around oil platforms and adjacent natural reefs near Santa Barbara, California. Fish. Bull. 88:599-605.

Lucifredi A, 2018. [Addio alle piattaforme].[Article in Italian]. Le Scienze 596:76-81.

Luckhurst BE, Luckhurst K, 1978. Analysis of the influence of the substrate variables on coral reef fish communities. Mar. Biol. 49:317-323.

MacArthur RH, Levins R, 1967. The limiting similarity, convergence and divergence of coexisting species. Am. Nat. 101:377-385.

Macpherson E, 1994. Substrate utilization in a Mediterranean littoral fish community. Mar. Ecol. Prog. Ser. 114:211-218.

Mangano MC, Bottari T, Caridi F, Porporato EMD, Rinelli P, Spanò N, Johnson M, Sarà G, 2017. The effectiveness of fish feeding behaviour in mirroring trawling-induced patterns. Mar. Environ. Res. 131:195-204.

Mangano MC, Kaiser MJ, Porporato EMD, Lambert GI, Spanò $\mathrm{N}, 2015$. Trawling disturbance effects on the trophic ecology of two co-generic Astropectinid species. Mediterr. Mar. Sci. 16:538-549.

Mangano MC, Sarà G, 2017. Collating science-based evidence to inform public opinion on the environmental effects of marine drilling platforms in the Mediterranean Sea. J. Environ. Manage. 188:195-202.

McArdle BH, Anderson MJ 2001. Fitting multivariate models to community data: a comment on distance-based redundancy analysis. Ecology 82:290-297.

McClanahan TR, 1994. Kenyan coral reef lagoon: effects of fishing, substrate complexity, and sea urchins. Coral Reefs 13:231-241.

McCormick MI, 1994. Comparison of field methods for measuring surface topography and their associations with a tropical reef fish community. Mar. Ecol. Prog. Ser. 112: 7-96.

Minton V, Heath SR, 1998. Alabama's artificial reef program: building oases in the desert Gulf. Mex. Sci. 16:105-106.

Ogawa Y, 1982. Reef materials and designs: examples of their applications, p. 320-364. In: S.F Vik (ed.), Japanese artificial reef technology. Tech. Rep. 604. Aquabio, Inc., Annapolis.

Öhman MC, Rajasuriya A, 1998. Relationships between habitat structure and fish communities on coral and sandstone reefs. Environ. Biol. Fishes 53:19-31.

OSPAR Commission, 1992. Convention for the protection of the marine environment of the North-East Atlantic. Available from: https://www.ospar.org/convention

Porporato EM, Mangano MC, De Domenico F, Giacobbe S, Spanò N, 2014. First observation of Pteroeides spinosum (Anthozoa: Octocorallia) fields in a Sicilian coastal zone (Central Mediterranean Sea). Mar. Biodivers. 44:589-592.

Pulsipher AG, Daniel WB, 2000. Onshore disposition of offshore oil and gas platforms: western politics and international standards. Ocean Coast. Manage. 43:973-995.

Relini G, Geraci S, Montanari M, Romairone V, 1976. [Variazioni stagionali del fouling sulle piattaforme off-shore di Ravenna e Crotone].[Article in Italian]. Boll. Pesca 31:227-256.

Rilov G, Benayahu Y, 1998. Vertical artificial structures as an alternative habitat for coral reef fishes in disturbed environments. Mar. Environ. Res. 45:431-451.

Rilov G, Benayahu Y, 2000. Fish assemblage on natural vs vertical artificial reefs: the rehabilitation perspective. Mar. Biol. 36:931-942.

Rilov G, Benayahu Y, 2002. Rehabilitation of coral reef-fish communities: the importance of artificial-reef relief to recruitment rates. Bull. Mar. Sci. 70:185-197.

Roberts CM, Ormond RFG, 1987. Habitat complexity and coral reef fish diversity and abundance on Red Sea fringing reefs. Mar. Ecol. Prog. Ser. 41:1-8.

Rooker JR, Dokken QR, Pattengill CV, Holt GJ, 1997. Fish assemblages on artificial and natural reefs in the Flower Garden Banks National Marine Sanctuary, USA. Coral Reefs 16:83-92.

Scarcella G, Grati F, Fabi G, 2011. Temporal and spatial variation of the fish assemblage around a gas platform in the Northern Adriatic Sea, Italy. Turk. J. Fish. Aquat. Sci. 11:433-444.

Schroeder DM, Love MS 2004. Ecological and political issues surrounding decommissioning of offshore oil facilities in the Southern California Bight. Ocean Coast. Manage. 47:21-48.

Stanley DR, Wilson CA, 1991. Factors affecting the abundance of selected fishes near oil and gas platforms in the northern Gulf of Mexico. Fish. Bull. 89:149-159.

Steimle FW, Ogren L, 1982. Food of fish collected on artificial reefs in the New York Bight and off Charleston, South Carolina. Mar. Fish. Rev. 44:49-52.

Terlizzi A, Bevilacqua S, Scuderi D, Fiorentino D, Guarnieri G, Giangrande A, Licciano M, Felline S, Fraschetti S, 2008. Effects of offshore platforms on soft-bottom macro-benthic assemblages: A case study in a Mediterranean gas field. Mar. Poll. Bull. 56:1303-1309.

Yoshimuda N, 1982. Discussion of installation planning, p. 137165. In: S.F Vik (ed.), Japanese artificial reef technology. Tech. Rep. 604. Aquabio, Inc., Annapolis.

Warfe DM, Barmuta LA, 2004. Habitat structural complexity mediates the foraging success of multiple predator species. Oecologia 141:171-178.

Willis SC, Winemiller KO, Lopez-Fernandez H, 2005. Habitat structural complexity and morphological diversity of fish assemblages in a Neotropical floodplain river. Oecologia $142: 284-295$. 